Egyptian

Orthodontic Journal

\title{
LOCATION OF PALATALLY IMPACTED CANINE AND ITS EFFECT ON ROOT RESORPTION USING CBCT
}

\author{
Samier F. Elhebieshy ${ }^{(1)}$, Sherif S. Morcos(2),
}

Ahmed A. Ramadan(3)

\section{ABSTRACT:}

Background: Maxillary canines are important aesthetically and functionally, but impacted canines are more difficult and time consuming to treat. Moreover, impacted canines vary greatly in the inclination and location and can lead to resorption of neighboring incisors. Aim: To locate the impacted canine and compare resorption cases with non-resorption cases. Methods: Thirty -five 3 D CBCT scans were evaluated 17 presented with Gilateral palatal impactions and 18 with unilateral impactions. Fifty -two canines were divided in two groups: group $\mathcal{A}$ : included impacted canines causing resorption to neighboring teeth and group $\mathfrak{B}$ : impacted canines not causing resorption. Canine axis inclination, horizontal cusp location and distance to nearest adjacent tooth were recorded. T-tests (paired, student) determined the significance ( $\mathrm{P} \leq 0.05)$ performed to evaluate the effect of resorption within and between each group. Results: Twenty-one canines caused resorption (40\%) of the lateral incisor while there were 31 canines not causing resorption. Palatally impacted canines causing resorption to the adjacent teeth showed higher inclination of their axis to the midsagittal plane. Conclusions: Palatally impacted canines have

1- Master degree candidate, resident orthodontic department, Faculty of Dentistry, Suez Canal University, Ismailia, Egypt

2- Lecturer, Orthodontic dept. Faculty of Dentistry, Suez Canal University, Ismailia, Egypt.

3- Professor, Orthodontic dept., Faculty of Dentistry, Suez Canal University, Ismailia, Egypt. 
Egyptian

Orthodontic Journal

high chance of causing resorption to adjacent teeth. As the canine is more medially located there is an increased chance of resorption especially when the cusp of the maxillary canine was positioned medially to the long axis of the lateral incisor. Highly significant correlation between palatally impacted canines in contact with neighboring teeth and resorption was found.

Keywords: Palatally impacted canine, CBCT, root resorption

\section{INTRODUCTION}

Permanent maxillary canines are the second most frequently impacted teeth after the third molars ${ }^{[1]}$. At the same time, maxillary canines are important esthetically and functionally ${ }^{[2]}$. Impacted canines can also lead to the resorption of neighboring permanent teeth, particularly the lateral incisors. Various degrees of resorption on the permanent incisors have been reported approximately $48 \%{ }^{[3]}$. Root resorption is defined as a condition of dental complication associated with either a physiological or pathological activity of the tooth resorbing cells, which results in loss of cementum and /or dentine ${ }^{[4]}$. Root resorption is very difficult to treat and usually requires extraction of the affected tooth. Impaction is defined as a failure of tooth eruption at its appropriate site in the dental arch within the normal period of growth based on clinical and radiographic assessment ${ }^{[1]}$. A common guideline for diagnosis of impactions: the presence of a tooth whose root is one-half to three-quarters developed whose unaided eruption is unlikely to occur ${ }^{[5]}$. Untreated maxillary canine impaction may result in several complications like displacement and loss of vitality of the adjacent incisor, shortening of the dental arch, formation of follicular cysts, canine ankylosis, recurrent infections, recurrent pain, internal resorption, external resorption of the canine and the adjacent teeth, or combination of these factors ${ }^{[6]}$. Early diagnosis of canine impaction allows for the early detection and prevention of canine impaction reducing treatment time, complexity, complications and $\operatorname{cost}^{[7]}$. Several 2D radiographic techniques have been used for differential diagnosis of root resorption, including periapical, occlusal, panoramic, and cephalometric radiographs or a combination of 
Egyptian

Orthodontic Journal

these approaches ${ }^{[8,9]}$. Treatment plans of 80 children with impacted maxillary canines before and after information gained from a CT examination. The result showed the information obtained from the CT images modified the treatment plans for $44 \%$ of the 80 children and $54 \%$ of those children showed incisor root resorption ${ }^{[10]}$. CBCT has been proven to be superior to other radiographic methods in visualizing the maxillofacial region among which diagnosing position and complications of ectopically erupting teeth ${ }^{[11,12,13,14]}$.

\section{METHODS:}

CBCT data was collected for 25 patients with palatally impacted canines seeking orthodontic treatment, 17 presented with bilateral palatal impactions and 18 with unilateral impactions giving a total of 52 palatally impacted canines. The mean age of the patients was 14 years ranging from 11 to 20 years old. The inclusion criteria were presence of at least one maxillary palatally impacted canine. CBCT image were acquired prior to the start of comprehensive orthodontic treatment. Fifty -two canines were divided in two groups: group A: included impacted canines causing resorption to neighboring teeth and group B: impacted canines without causing resorption to neighboring teeth.

Imaging Device: These patient's CBCT scans were obtained from the pro max 3D Planmeca Romexis Scanner (Planmeca Medical Systems, Helsinki, Finland), using a 12 inch field of view with a voxel size of $0.377 \mathrm{~mm}$ according to the manufacturer's instruction.

Image Manipulation: The images were reconstructed by the special software program of pro max 3D Planmeca Romexis X-ray machine named RomexisViewer (Planmeca Medical Systems, Helsinki, Finland), with this software it is possible to view the different cuts at increasing magnifications for better accuracy. The Software was used for analysis and data collection of linear and angular measurements.

The axial plane was registered to the maxillary occlusal plane, since efforts to align the palatally impacted canine are conducted with respect to this plane of reference. This plane was established parallel to the marginal ridges and cusp tips of the fully erupted premolars and central incisors $^{[3]}$. The midsagittal plane was registered to the skeletal midsagittal 
Egyptian

Orthodontic Journal

plane, which frequently corresponded to the maxillary dental midline. The coronal plane was, by definition, oriented perpendicular to the axial and sagittal planes.

A linear and angular measurement of the inclination was taken and three dimensional locations of the impacted canines to the maxillary structures were assessed. These measurements were made on axial, coronal and transaxial views ${ }^{[14]}$.

From the coronal, axial and trans-axial view the following measurements were taken:

- The impacted crown's horizontal position were distributed to 4 sectors according to Ericson and Kurol ${ }^{[7]}$ (Fig. 1)

- The angle between the canine axis and the midline was calculated according to Ericson and Kurol ${ }^{[3]}$. (Fig. 3 )

- The resorption of the incisors was assessed by axial and transaxial views according to Ericson and Kurol ${ }^{[16]}$ and categorized into cases with shown resorption (any grade) and cases without resorption.

- The distance to the nearest adjacent tooth was recorded. (Fig. 3)

\section{Legend of illustrations}

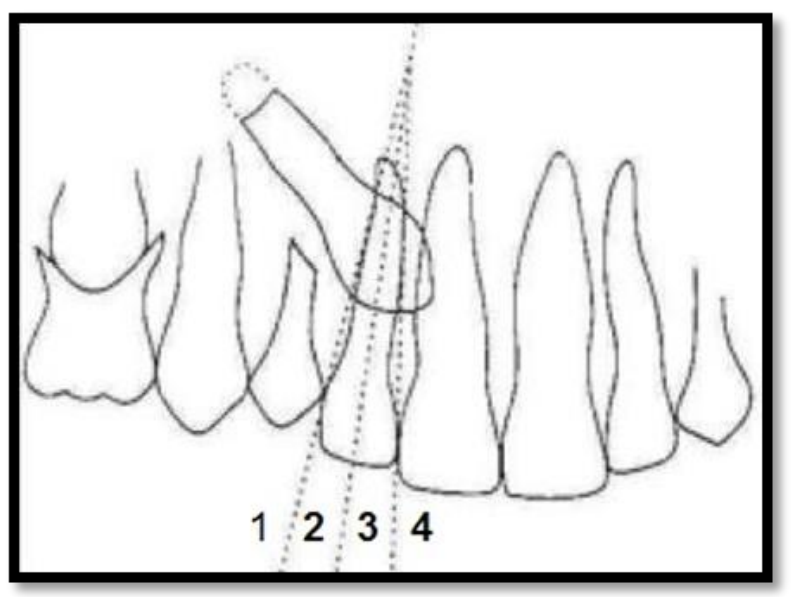

Figure 1: Illustration showing various sectors according to Ericson and Kurol's criteria.

Volume 48 - December 2015 


\section{Egyptian \\ Orthodontic Journal}

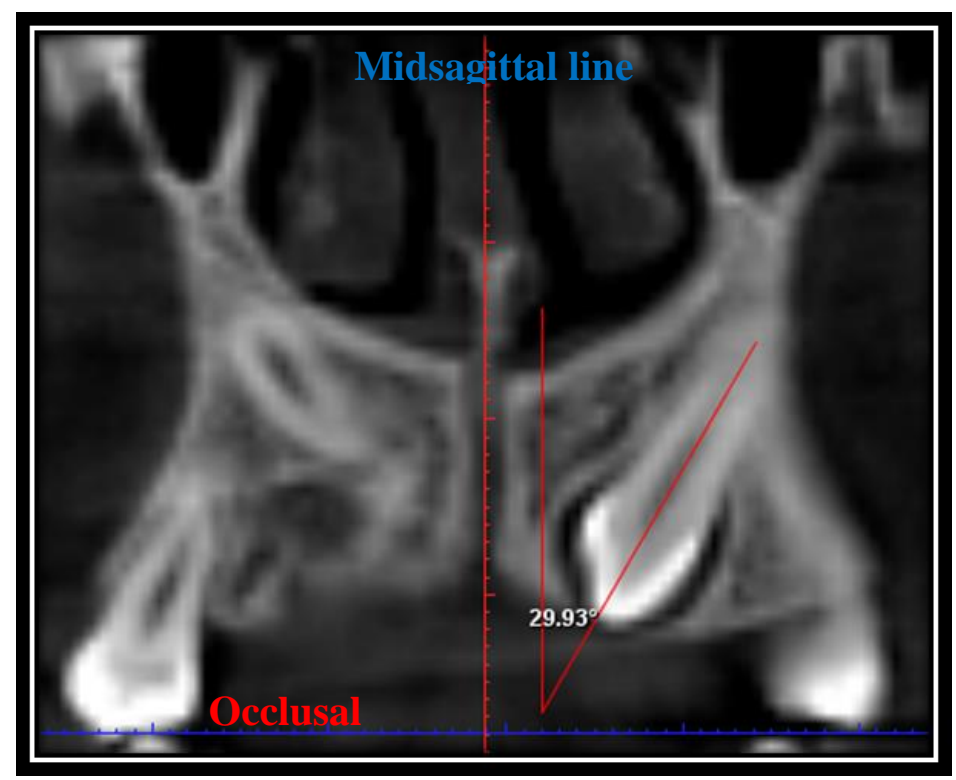

Figure3: Image showing the angle between the canine axis and the midline.

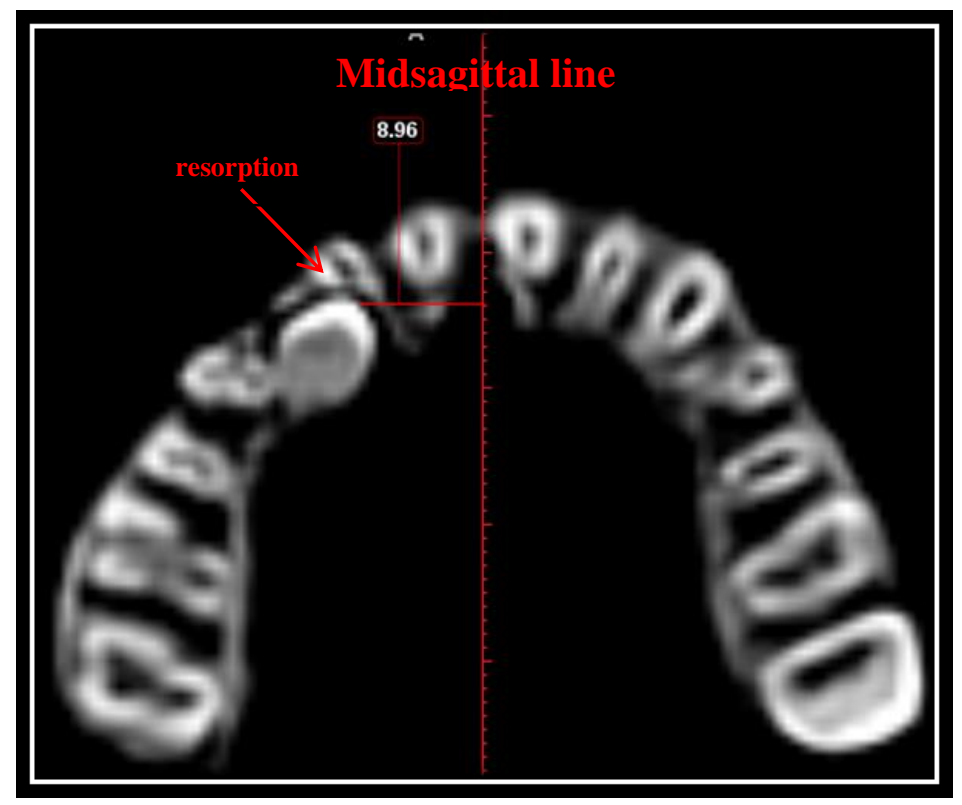

Figure 4: Image showing resorption to lateral incisor in the axial view. 
Egyptian

Orthodontic Journal

One way analysis of variance (SPSS, analyze, compare means, one way ANOVA) ${ }^{54}$ was used to test the effect of direction, resorption, or horizontal zone of the cusp tip. Duncan Post-Hoc Multiple Comparisons (Post-Hoc) at $\mathrm{p} \leq 0.05$ was used for means comparison.

T-tests (paired, student) determined the significance $(\mathrm{P} \leq 0.05)$ performed to evaluate the effect of resorption within and between each group.

\section{RESULTS}

Thirty -five 3D CBCT scans were evaluated, 17 presented with bilateral palatal impactions and 18 with unilateral impactions, twenty one of the 52 palatally impacted canines caused resorption of the lateral incisor resulting in a resorption rate of $40 \%$. Of these 21 impacted canines 3 involved resorption of the central incisor. Thirty one teeth showed canine contact less than 0.5. Nineteen were resorbed $(61.29 \%)$, whereas only 2 out of 21 resorbed teeth had no canine contact were as shown in table (1).

Six impacted canines were found in sector 1, 19 in sector 2, 12 in sector 3 and 15 in sector 4. (Graph 1)

Sixteen $\%$ (one) of the impacted canines found in sector 1 caused resorption, $42 \%$ (eight) of the impacted canines found in sector 2 caused resorption, $50 \%$ (six) of the impacted canines found in sector 3 caused resorption and $40 \%$ (six) of the impacted canines found in sector 4 caused resorption as shown in graph (2).

Measurements showed that the mean angle between the axis of the impacted maxillary canines and the mid sagittal plane in the frontal view were 13.455 degree for impactions not causing resorption and 24.417 degree for impactions causing resorption as shown in Table (2) \& Graph (3).

Measurements showed that the mean angle between the axis of the impacted maxillary canines and the mid sagittal plane in the frontal view was 16.833 degree for impactions in sector 1 , and 19.805 degree for impactions in sector 2, 29.250 degree for impactions in sector 3 and 38.533 degree for impactions in sector 4. Table (3)

Volume 48-December 2015 
Egyptian

Orthodontic Journal

\section{Legend of tables}

Table (1): Table showing the distribution of the cases involving resorption in relation to canine contact.

\begin{tabular}{|l|c|c|c|c|}
\hline & $\begin{array}{c}\text { canine contact } \\
\text { less than } \mathbf{0 . 5} \mathbf{~ m m}\end{array}$ & $\begin{array}{c}\text { canine contact } \\
\text { more than } \mathbf{0 . 5} \mathbf{~ m m}\end{array}$ & \multicolumn{2}{|c|}{ total } \\
\hline Resorption & & & No. & $\%$ \\
\hline Yes & 19 & 2 & 21 & 40.38 \\
\hline No & 12 & 19 & 31 & 59.62 \\
\hline Total & 31 & 21 & 52 & 100.0 \\
\hline
\end{tabular}

$\square$ Sector 1 Sector $2 \square$ Sector $3 \square$ Sector 4

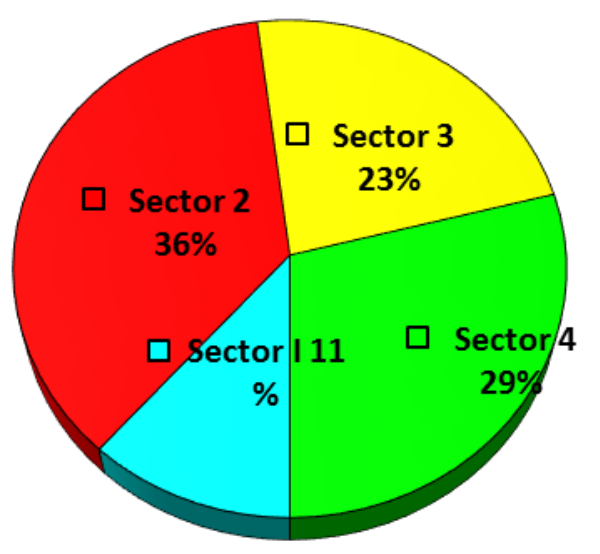

Graph (1): Showing the prevalence of horizontal zone distribution of the cusp tip in palatal impacted canines $(n=52)$. 


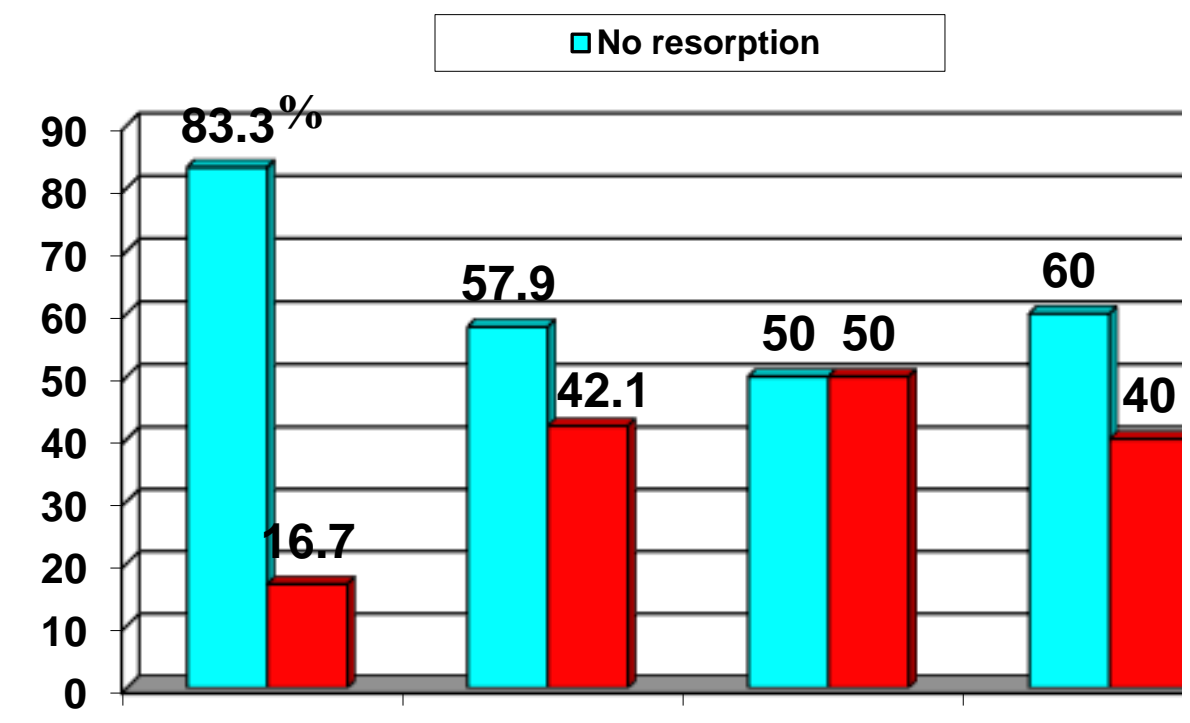

Graph (2): Graph showing the relationship between resorption occurrence and horizontal zone of the cusp tip.

Table (2): Table showing the descriptive statistics and test of significance for the effect of resorption on different parameters.

\begin{tabular}{|l|c|c|c|c|c|}
\cline { 2 - 5 } \multicolumn{1}{c|}{ Parameter } & \multicolumn{4}{c|}{ No } & \multicolumn{2}{c|}{ Yes } & \multirow{2}{*}{ p } \\
\cline { 2 - 5 } & Mean & S.D. & Mean & S.D. & \\
\hline Age & 13.571 & 3.075 & 14.130 & 3.152 & 0.449 NS \\
\hline Axis with midline & 13.455 & 17.271 & 24.417 & 16.464 & $0.008 * *$ \\
\hline
\end{tabular}

S.D. = Standard deviation.

$\mathrm{P}=$ Probability level for the effect of resorption.

NS $=$ Insignificant $(\mathrm{P}>0.05)$

* $\quad=$ Significant at $\mathrm{p} \leq 0.05$

Total resorption (yes) $=21$

Total resorption $(\mathrm{no})=52$

Volume 48-Decem6er 2015 


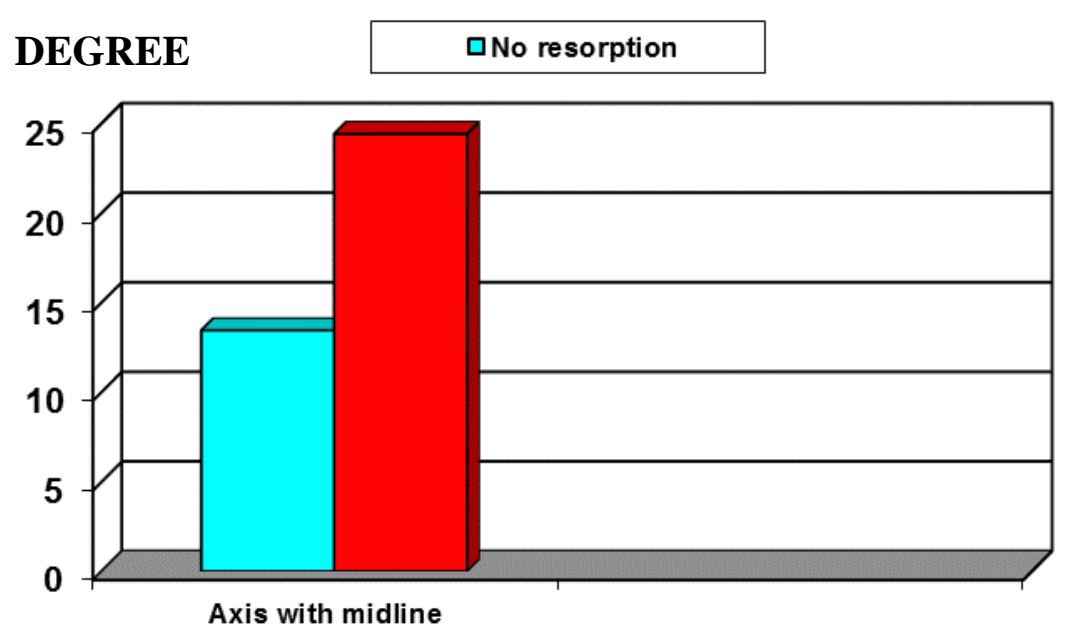

Graph (3): Graph showing the mean canine axis angle with the midline in the frontal view in non-resorption and resorption groups.

Table (3): Showing the descriptive statistics and test of significance for the effect of horizontal zone of the cusp tip on axis angle of palatal impacted canines.

\begin{tabular}{|l|c|c|c|c|c|c|c|c|c|c|c|c|}
\hline \multirow{2}{*}{ Parameter } & \multicolumn{3}{|c|}{ Sector 1 } & \multicolumn{3}{c|}{ Sector 2 } & \multicolumn{3}{c|}{ Sector 3 } & \multicolumn{3}{c|}{ Sector 4 } \\
\cline { 2 - 13 } & Mean & S.D. & dt & Mean & S.D. & dt & Mean & S.D. & dt & Mean & S.D. & dt \\
\hline Age & 15.000 & 2.966 & a & 15.368 & 2.650 & a & 13.083 & 1.832 & b & 15.133 & 3.378 & a \\
\hline $\begin{array}{l}\text { Axis with } \\
\text { midline }\end{array}$ & 9.833 & 11.409 & b & 18.805 & 11.255 & b & 29.250 & 9.363 & a & 38.533 & 12.357 & a \\
\hline
\end{tabular}

S.D. = Standard deviation.

dt = Duncan's Multiple Range Test for the effect of horizontal zone distribution of the cusp tip.

Means with the same letter within each row are not significantly different at $\mathrm{p}=0.05$

\section{DISCUSSION}

For locating of the palatally impacted canine and its effect on root resorption, 52 impacted canines were diagnosed from C.B.C.T in patients seeking orthodontic treatment. Eighteen cases presented with unilateral impacted canines and 17 cases were bilateral impactions giving a total of 52 impacted canines. This study showed six impacted canines in sector 1 , 


\section{Egyptian \\ Orthodontic Journal}

while 19 in sector 2 , with 12 in sector 3 and 15 in sector 4 which was not in agreement with other studies ${ }^{[15]}$. In this study $40 \%$ of the palatal impacted canines caused resorption in adjacent lateral incisor. The percentage of incisor resorption was comparable with previous reports in a CT study of 156 ectopically impacted maxillary canines $(38 \%)^{[7]}$, and was lower than the reported percentage of $66.7 \%^{[14]}$. The possible reasons for these differences may be related to the differences in diagnostic technique, sampling of the subjects and their age range.

Therefore, resorption of incisor is a common phenomenon and should be anticipated in all patients with impacted canines. ${ }^{[3,13]}$. Measurements showed that the mean angle between the axis of the impacted maxillary canines and the mid sagittal plane in the frontal view were 13.455 degree for impactions not causing resorption and 24.417 degree for impactions causing resorption. Results showed that as the canine is more medially located there is a higher resorption rate specially when the cusp of the maxillary canine was positioned medially to the long axis of the lateral incisor. This indicates the close relationship between resorption and the eruption path of the canine and the neighbor teeth this was in agreement with other ${ }^{[3]}$.

The results of this study showed that $19(61.3 \%)$ out of the 31 canines which had contact with the adjacent teeth and $12(38.7 \%)$ cases showed contact with the adjacent teeth but without resorption indicating that incisor resorption was significantly correlated with contact between the incisor and impacted canine. This was in agreement with other studies ${ }^{[16]}$.

\section{CONCLUSIONS}

Early diagnosis of impacted canine and root resorption can reduce complications during treatment and the presence or absence of root resorption will determine the treatment plan.

The severity of lateral incisor root resorption cannot be accurately judged from two dimensional radiographs alone. CBCT has a smaller radiation dose compared to $\mathrm{CT}$ and overcomes the limitations of conventional radiography. Therefore, CBCT is a useful method for diagnosing the position, inclination, distance from adjacent structures, complications of impacted canines, and detection of lateral incisors root resorption.

Volume 48 - December 2015 
- In this study $40 \%$ of the palatal impacted canines caused resorption in adjacent lateral incisor.

- Results showed that "as the canine is more medially located" there is an increased chance of resorption specially when the cusp of the maxillary canine was positioned medially to the long axis of the lateral incisor.

- Palatally impacted canines causing resorption to the adjacent teeth showed higher angles of their axis to the midsagittal plane.

- Highly significant correlation between contact and resorption was found.

\section{REFERENCES}

1. Thilander B, Jakobsson SO. Local factors in impaction of maxillary canines. Acta Odontol Scand. 1968; 26(2):145-68.

2. Freisfeld M, Dahl IA, Jäger A et al .X-ray diagnosis of impacted upper canines in panoramic radiographs and computed tomographs. J Orofac Orthop $1999 ; 60: 177-184$

3. Ericson S, Kurol J. Resorption of maxillary lateral incisors caused by ectopic eruption of the canines. A clinical and radiographic analysis of predisposing factors. Am J Orthod Dentofacial Orthop 1988; 94:503-513

4. Tronstad L. Root resorption - etiology, terminology and clinical manifestations. Endodont Dent Traumatol 1988; 4:241-252

5. Becker A. Orthodontic Treatment of Impacted Teeth. New York, NY: Informa Healthcare; 2007.

6. Shafer WG, Hine MK, Levy BM. A textbook of oral pathology, 4th edn. W.B. Sauders, Philadelphia 1984

7. Ericson S, Kurol J. Radiographic assessment of maxillary canine eruption in children with clinical signs of eruption disturbance. Eur J Orthod 1986 8:133-140 
Egyptian

Orthodontic Journal

8. Mason C, Papadakou P, Roberts GJ. The radiographic localization of impacted canines: a comparison of methods. Eur J Orthod 2003; 23:25-34

9. Maverna R, Gracco A.Different diagnostic tools for the localization of impacted maxillary canines: clinical considerations. Prog Orthod 2007; 8:28-44

10. Bjerklin K, Ericson S. How a computerized tomography examination changed the treatment plans of 80 children with retained and ectopically positioned maxillary canines. Angle Orthod 2006; 76:43-51

11. Chen Y, Duan P, Meng Y et al. Three-dimensional spiral computed tomographic imaging: a new approach to the diagnosis and treatment planning of impacted teeth. Am J Orthod Dentofacial Orthop 2006; 130:112-116

12. Korbmacher H, Kahl-Nieke B, Schöllchen $M$ et al. Value of two cone-beam computed tomography systems from an orthodontic point of view. J Orofac Orthop 2007; 68:278-289

13. Liu DG, Zhang WL, Zang ZY et al. Localization of impacted maxillary canines and observation of adjacent incisor resorption with cone-beam computed tomography. Oral Surg Oral Med Oral Pathol Oral Radiol Endod 2008; 105:91-98

14. Walker L, Enciso R, Mah J. Three-dimensional localization of maxillary canines with cone-beam computed tomography. Am J Orthod Dentofacial Orthop 2005; 128:418-423

15. Nagpal A, Pai KM, Setty S, Sharma G. Localization of impacted maxillary canines using panoramic radiography. J Oral Sci. 2009 Mar; 51(1):37-45.

16. Ericson S, Kurol J. Resorption of incisors after ectopic eruption of maxillary canines: a CT study. Angle Orthod 2000; 70:415- 423. 